\title{
Which One Should We Perform for Native Nephrectomy in Renal Transplant Recipients with Polycystic Kidney Disease: Bilateral or Unilateral Nephrectomy? Eight Years Experience in Our Transplantation Centre
}

\author{
Yucel*, Tekin $\mathrm{S}^{2}$,Yuksel $\mathrm{D}^{3}$, Yucetin $\mathrm{L}^{1}$, Yavuz $\mathrm{H}$ Asuman ${ }^{4}$ and Demirbas $\mathrm{A}^{1}$ \\ ${ }^{1}$ Department of General Surgery and Transplantation, Medical Park Hospital, Turkey \\ ${ }^{2}$ Department of General Surgery, Kemerburgaz University, Istanbul \\ ${ }^{3}$ Department of Anesthesia and Reanimasyon Unit, Training and Research Hospital, Antalya \\ ${ }^{4}$ Department of Nephrology and Transplantation, Medical Park Hospital, Antalya
}

Submission: February 07, 2017; Published: April 11, 2017

*Corresponding author: Yucel, Department of General Surgery and Transplantation, Medical Park Hospital, Turkey,

Email: dryucelyuksel@gmail.com

Keywords: Autosomal-dominant polycystic kidney disease (ADPKD kidney transplant, complications)

Abbreviations: ADPKD: Autosomal Dominant Polycystic Kidney Disease; RT: Renal Transplantation; BNN: Bilateral Native Nephrectomy; UNN: Unilateral Native Nephrectomy; ICU: Intensive Care Unit

\section{Introduction}

Autosomal-dominant Polycystic kidney disease (ADPKD) is frequently seen with an incidence of $1: 1000$ in patients [1]. It systemically involves multi-organs such as liveric cysts, colonic diverticules, aorta and intracranial aneurysms [2-4]. Most of these patients are asymptomatic till progressing to end stage renal failure [5]. ADPKD is characterized with on growing multiple renal parenchymal cysts which leads to $70 \%$ renal insufficiency on the fifth or sixth decades of life $[6,7]$. Its urologic complications include pyelonephritis, nephrolithiasis, gross hematuria due to hemorrhage of cysts, urosepsis and renal colic while as systemic complications include hypertension, abdominal distension and pain $[1,3,8,9]$. ADPKD is responsible for approximately $10 \%$ of all cases of end stage renal disease whose curative therapy is renal transplantation [10].

There is not any consensus among clinicians for performing native nephrectomy relative to kidney transplantations for patients with ADPKD [5,11,12]. Historically in 1970s bilateral native nephrectomy was routinely performed 1 to 250 weeks before transplantation till realizing this procedures complications during anaphoric state such as fluid overload, congestive heart disease, hyperkalemia, renal osteodystrophy and anemia due to the lack of erythropoietin production $[3,5,12,13]$. In early, 1980 s some centers started to perform 'Sandwich Technique'. One side native nephrectomy was performed before and the other side native nephrectomy was performed after transplantation in sandwich procedure which needed 3 separate undesirable operations [5-12]. Later Glassman and Fuller reported unilateral native nephrectomy concurrent with renal transplantation from the Gibsons incision $[10,12,13]$.

In this study, we purposed to analyze the results of renal transplantations with concurrent bilateral or unilateral native nephrectomy in APKD patients by comparing the length of stay in ICU after operation, the inotropic demand in ICU and the complications we observed after these procedures.

\section{Materials and Methods}

3924 renal transplantations at Antalya Medical Park Transplantation Centre between 2008 November -2016 October. The data was collected retrospectively from the patients who gave written consent about the study. 123 patients with ADPKD were undergone native nephrectomy surgery with concomitant renal transplantation. Patient's age and gender, type and duration of dialysis, number of transplantations, cadaveric or living donor type, the size and weight of native kidneys were investigated. All the patients were divided into two groups as bilateral native nephrectomy (BNN) or unilateral native nephrectomy (UNN) 
groups. The length of stay in ICU after operation, the inotropic demand in ICU and the complications we observed after these procedures were compared among the groups (Figure 1).

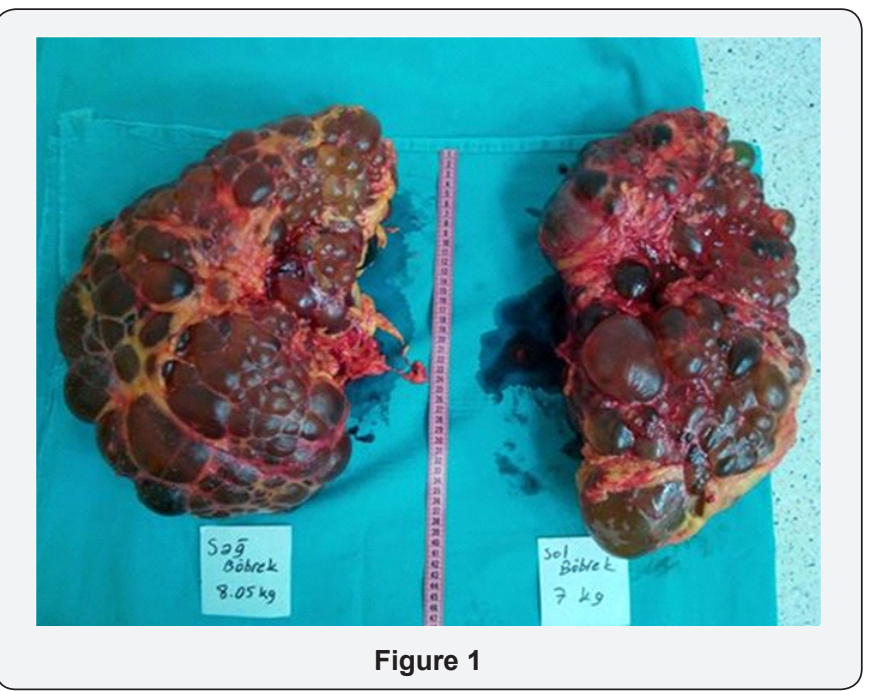

\section{Statistical analysis}

Data was evaluated by using SPSS 16.0 program. Number, percentage, mean variation, Student t test, ki square, turkey HSD and man Whitney U tests were used for data analysis.

\section{Surgical procedure}

BNN: Median laparotomy is used for trans peritoneal approach to abdomen. Bowel ANS are released from posterior abdominal wall at White line to reach retroperitonium for left kidney. Left kidney is released from pancreatic tail, spleen and diaphragm after finding and following left ureter up to the kidney. Left nephrectomy is completed after renal artery, vein and ureter are ligatured and cut from the far distal. We follow the same procedures for the removal of right kidney except releasing the kidney from liver, duodenum and ascendant colon on the right side of the body.

UNN: Gibson incision is used to reach retroperitonium. The kidney hilus is exposed by following ureter and is separated from adrenal gland under liver. Nephrectomy is completed after dissecting renal artery, vein and ureter. Peritoneal gaps are closed to avoid internal herniation and to prepare the iliac area for graft kidney.

\section{Results}

We performed 3924 renal transplantations at Antalya Medical Park Transplantation Center between November 2008-October 2016.123 renal transplant patients had ADPKD. Donor type was living donor in 118 transplantations and cadaveric donor in 5 transplantations. 78 of the patients were male and 45 of the patients were female. The mean age was 49,8 $\pm 7,6$ (28-67). Mean BMI was $25.6 \pm 5.0$ (20.8-33.6), 51 patients were preemptive, 68 patients were having hemodialysis, 1 patient was having peritone dialysis while 3 patients were having both hemodialysis and peritone dialysis. The duration of dialysis was $24.2 \pm 43.4$ (0216) months.

We performed bilateral native nephrectomy to 35 of renal transplant ADPKD patients. 20 of the patients were male and 15 of the patients were female. The mean age was $50.6 \pm 6.8$ (35-67). Mean BMI was 24.8 \pm 5.1 (20.6-34.4), 14 patients were preemptive, 20 patients were having hemodialysis while 1 patient was having both hemodialysis and peritone dialysis. 20 patients were accepted to Intensive care unit (ICU) during postoperative period because of acidosis and hypotension resistant to high dose inotropic agents. 4 patients required splenectomy because of iatrogenic splenic injury. 1 patient died on postoperative $9^{\text {th }}$ day at ICU and 1 patient recovered after cardiopulmonary arrest during ICU stay.

We performed unilateral native nephrectomy to 88 of renal transplant ADPKD patients. 58 of the patients were male and 30 of the patients were female. The mean age was $49.5 \pm 7.9$ (28-67). Mean BMI was 26.6 \pm 5.2 (22.1-38.5), 37 patients were preemptive,48 patients were having hemodialysis, 1 patient was having peritone dialysis while 2 patients were having both hemodialysis and peritone dialysis. Only 1 patient required ICU stay during postoperative period because of comorbidities but no patient suffered from inotropic resistant hipotension. Additional organ injury and ileus were not observed .

The size of the right kidneys as width $\times$ length $\times$ height were mean $24,6 \times 14.6 \times 9.2 \mathrm{~cm}$, maximum $52 \times 30 \times 16 \mathrm{~cm}$ and $11 \times 5 \times 3.5 \mathrm{~cm}$ minimum and $1980 \mathrm{gr}(510-8050 \mathrm{gr})$ of weight. The size of the left kidneys as width $\times$ length $\times$ height were mean $24,2 \times 14.8 \times 10.7 \mathrm{~cm}$, maximum $48 \times 30 \times 16 \mathrm{~cm}$ and $13 \times 6 \times 3 \mathrm{~cm}$ minimum and 2351gr (519-7000gr) of weight.

\section{Discussion}

Optimal timing for native nephrectomy for patients with ADPKD and its necessity is still controversial and quite different among transplantation centers $[5,11,12]$. In the past, pretransplant unilateral or bilateral nephrectomy was recommended for patients with ADPKD who had pain, infection, hemorrhage, hypertension and impression symptoms [11]. The incidence of pretransplant native nephrectomy decreased in the last 20 years due to the development of conservative treatments and increased use of potent antibiotics, analgesics and anti-hypertensive agents [11]. Brazda, et al. found higher graft and patient survival rates among ADPKD patients who had undergone a pretransplant unilateral nephrectomy [11]. Many recent publications point that pretransplant unilateral or bilateral native nephrectomy is associated with higher mortality and morbidity [6]. Unilateral nephrectomy with concurrent transplantations is only suggested if the native kidney is too big to occupy the graft kidneys place [6]. We do not routinely prefer simultaneous nephrectomy in our transplantation center except to provide adequate place for graft kidney and to prevent the compressions on graft. Unilateral native nephrectomy with 
renal transplantation is made from the Gibson incision for Grade 5 vesicoureteral reflux, cohesion due to the pyelonephritis and for huge native kidneys. For grade 3-4 vesicoureteral reflux, we prefer to perform laparoscopic bilateral native nephrectomy after transplantation period if the source of recurrent urinary tract infections is native kidneys.

Iatrogenic hepatic, splenic, intestinal and gastric injuries, ileus and hemorrhage are reported during bilateral native nephrectomy operations of ADPKD patients [12,13]. We experienced intestinal obstruction and splenic injury at our BNN operations. The continued cyst growth in ADPKD leads to the compression and cohesion of liver and spleen to each other at the upper pole and this status causes hemorrhage during dissection especially from the fragile spleen and liver organs.

There is not sufficient data about polycystic kidneys dimensions and weights on literature. In our case series, the weights of right kidneys of 52 patients according to the pathology results were more than $2000 \mathrm{gr}$ and maximum $8050 \mathrm{gr}$ while as the weights of left kidneys of 12 patients were more than $2000 \mathrm{gr}$ and maximum $7000 \mathrm{gr}$. The average weight of normal kidney of an adult is 120-150gr [14]. Our experiences show that there is certain blood loss from intravascular area of large kidneys more than 2000gr in weight during native nephrectomy even if with no bleeding from surgical site. Therefore, we transfuse at least 1 package of RBC before clamping the artery and vein of large native kidneys whose length are more than $20 \mathrm{~cm}$ during bilateral nephrectomy concurrent with graft transplantation surgeries in our center.

There is not again sufficient data about suprarenal injury during BNN concurrent with renal transplantation operations on literature. Suprarenal gland is located between liver and kidney on the right while as it is located between spleen and kidney on the left [14]. The average size of suprarenal glands as width $\times$ length $\times$ height are $5 \times 3 \times 1 \mathrm{~cm}$ [14]. Our experiences showed that the size of suprarenal glands of patients with ADPKD decrease $0.9 \mathrm{~cm}$ in width and increase in length because of the compression between expanding kidneys and liver/spleen. Tapering suprarenal gland is exposed to injury and even at the risk of amputation during nephrectomy procedure. The probable bilateral suprarenalectomy during bilateral native nephrectomy operations can cause hypotension resistant to vasoactive agents because of decreased neuroendocrine response and increased surgical bleeding which all increase the demand and length of ICU stay with increased morbidity and mortality [15]. In our case series, 20 patients among 35 total patients who had BNN concurrent with renal transplantations required ICU stay because of hypotension resistant to vasoactive agents. Therefore, surgeons should take twice as much care on BNN operations of ADPKD patients because of the expanding size of kidneys and cohesions resulting from pyelonephritic attacks.

Fuller, et al. and Glassman, etal. reported that unilateral native nephrectomy of ADPKD patients concurrent with transplantation is safe. If it is performed from Gibson incision $[10,13]$. We extend the Gibson incision to the curve of ribs for these surgeries at our centre. The kidneys in ADPKD expand slowly year by year forming a dissection line around them. Intestinal and abdominal organ injuries are lesser from this incision because of the chance of retroperitoneal dissection for nephrectomy. The difficult part of this procedure is the separation of cohesive kidney and liver at the upper pole and more attention must be taken to prevent injury of suprarenal gland at the upper pole. Peritoneal gaps should be closed to avoid internal herniation. Gibson incision approach provides earlier oral intake on the first post operative day compared with median approach as a result of preventing the intestinal injury and decreasing the probability of intestinal obstruction.

Compared with bilateral native nephrectomy unilateral nephrectomy provides better patient outcomes such as decreased demand and length of stay in ICU, decreased additional organ injuries and morbidity because of the presence of kidney and suprarenal gland of other side and because of shortness of operation time we recommend UNN from Gibson incision concurrent with renal transplantation for ADPKD patients because of the increased morbidity of BNN procedures.

\section{Acknowledgement}

We performed 3924 renal transplantations during 8 year period in our transplantation centre. Our experiences emphasize that bilateral native nephrectomies from median incision lead bilateral suprarenal and additional other organ injuries as well as excess blood loss to intravascular area of two kidneys independent from surgical area bleeding. Therefore, we recommend UNN from Gibson incision concurrent with renal transplantation for ADPKD patients for less morbidity .Further studies should be designed to search the effects and results of suprarenal injury during BNN procedures of ADPKD patients.

\section{References}

1. Chebib FT, Prieto M, Yeonsoon J, Irazabal MV, Kremers MK, et al. (2015) Native nephrectomy in renal transplant recipients with autosomaldominant polycystic kidney disease. Transplant Direct 1(10): e43.

2. Tyson MD, Wisenbaugh ES, Andrews PE, Castle EP, Humphreys MR (2013) Simultaneous kidney transplantation and bilateral native nephrectomy for polycystic kidney disease. J Urol 190(6): 2170-2174.

3. Rozanski J, Kozlowska I, Myslak M, Domanski L, Sienko J, et al. (2005) Pretransplant nephrectomy in patients with autosomal dominant polycystic kidney disease. Transplant Proc 37(2): 666-668.

4. Rodriguez-Faba O, Breda A, Villavicencio H (2014) Renal transplantation and polycystic: surgical considerations. Actas Urol Esp 38(1): 28-33.

5. Skauby MH, Øyen O, Hartman A, Leivestad T, Wadström J (2012) Kidney transplantation with and without simultaneous bilateral native nephrectomy in patients with polycystic kidney disease: a comparative retrospective study. Transplantation 94(4): 383-388.

6. Veroux M, Zerbo D, Palmucci S, Sinagra N, Giaquinta A, et al (2016) Simultaneous Nephrectomy and Ipsilateral Dual Kidney Transplantation in Patients With Autosomal Polycystic Kidney Disease. Transplantation 100(1): e3-e4. 
7. Kim JH, Chae SY, Bae HJ, Kim JI, Moon IS, et al. (2016) Clinical Outcome of Simultaneous Native Nephrectomy and Kidney Transplantation in Patients with Autosomal Dominant Polycystic Kidney Disease. Transplant Proc 48(3): 840-843.

8. Kramer A, Sausville J, Haririan A, Bartlett S, Cooper M, et al. (2009) Simultaneous Bilateral Native Nephrectomy and Living Donor Renal Transplantation are Successful for Polycystic Kidney Disease. J Urol 181(2): 724-728.

9. Król R, Ziaja J, Cierniak T, Pawlicki J, Chudek J, et al. (2006) Simultaneous transabdominal bilateral nephrectomy in potential kidney transplant recipients. Transplant 38(1): 28-30.

10. Fuller TF, Brennan TV, Feng S, Kang SM, Stock PG, et al. (2005) End Stage Polycystic Kidney Disease: Indications and Timing of Native Nephrectomy Relative To Kidney Transplantation. J Urol 174(6): 2284 2288.
11. Nunes P, Mota A, Alves R, Figueiredo A, Parada B, et al. (2007) Simultaneous Renal Transplantation and Native Nephrectomy in Patients With Autosomal-Dominant Polycystic Kidney Disease. Transplant Proc 39(8): 2483-2485.

12. Dinckan A, Kocak H, Tekin A, Urkyilmaz S, Hadimioglu N, et al. (2013) Concurrent unilateral or bilateral native nephrectomy in kidney transplant recipients. Ann Transplant 18(1): 697-704.

13. Glassman DT, Nipkow L, Bartlett ST, Jacobs SC (2000) Bilateral Nephrectomy with Concomitant Renal Graft Transplantation for Autosomal Dominant Polycystic Kidney Disease. J Urol 164: 661-664.

14. Farndon JR (1984) Endocrine Surgery Update. Ann Surg 200(5): 674.

15. Jansen AS, Nguyen KV, Karpitskiy V, Mettenleiter TC, Loewy AD (1995) Central command neurons of the sympathetic nervous system: basis of the fight-or-flight response. Science 270(5236): 644-646.

\section{Your next submission with Juniper Publishers will reach you the below assets}

- Quality Editorial service

- Swift Peer Review

- Reprints availability

- E-prints Service

- Manuscript Podcast for convenient understanding

- Global attainment for your research

- Manuscript accessibility in different formats

( Pdf, E-pub, Full Text, Audio)

- Unceasing customer service

Track the below URL for one-step submission https://juniperpublishers.com/online-submission.php 